\title{
Robert W. Bucholz, Charles M. Court-Brown, James D. Heckman, Paul Tornetta III (Eds.). Margaret M. McQueen, William M. Ricci (Ass. Eds.): Rockwood and Green's fractures in adults, 7th edn
}

\section{Lippincott, Williams \& Wilkins, Philadelphia, 2296 pp, ill.: 3900, December 2009, 449,00 \\ USD, ISBN 13: 978-1-60547-677-3}

\section{Pierre Kehr}

Received: 24 November 2011 / Accepted: 26 November 2011/Published online: 7 December 2011

(C) Springer-Verlag 2011

"The encyclopedia par excellence of traumatology".

This one is complete with precise descriptions since the diagnosis with classifications until the treatment while passing by the complications. Drawings and photographs unfortunately in black and white supplement each chapter. It is not a question, however, of a book of techniques.

Practically, all the fractures are described as well upper limbs and inferiors that pelvis or column. At the beginning of the book, one finds the principles general of treatment of the fractures.

Two characteristics of this book are interesting. A table of the various treatments with the respective advantages and disadvantages quickly makes it possible to have its idea and to choose "the good" treatment.

In addition, the preferred method of the author enables him to personalize a chapter, when exists a list of possibilities and thus allows to support a way of doing which proved reliable.

The bibliographies are very complete although very American.

The access to Internet site makes it possible to have access to video-movies.

This book is with being advised with all those which practice traumatology that it is senior or resident.

Alain Graftiaux

Strasbourg

Conflict of interest None.

P. Kehr ( () 